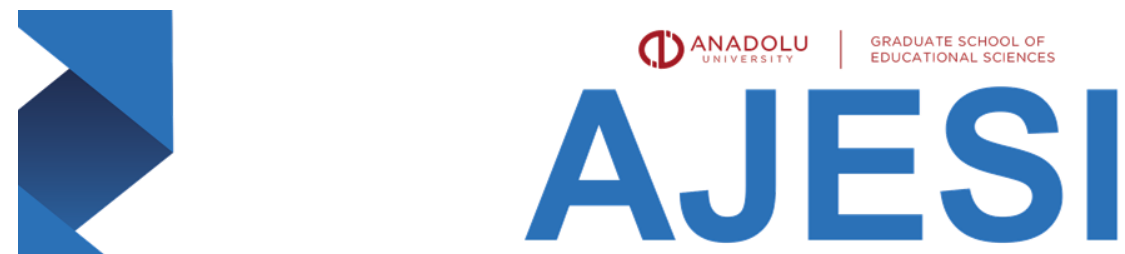

ANADOLU JOURNAL OF EDUCATIONAL SCIENCES INTERNATIONAL

DOI: 10.18039/ajesi.687143

\title{
Ambivalent Sexism, Interpersonal Relationships and Attributional Complexity of School Counselors in Istanbul ${ }^{1}$
}

Feyza DİNÇER ${ }^{2}$, Seyfi KENAN 3 , Seval ERDEN ÇINAR ${ }^{4}$

Submitted by: 17.02.2020

Accepted by: 16.12 .2020

Type: Research Article

\begin{abstract}
Since school counselors became an internal part of the school system, they are responsible for promoting psychological and mental health of their students as well as providing guidance for them. In order to fulfill these responsibilities, school counselors are expected to have empathetic, inclusive, democratic, and egalitarian attitudes. As a repercussion of these required such attitudes, the school counselors are expected to treat every person equally regardless of their gender, race, and lifestyle, and not to discriminate people based on their attributions, and maintain healthy interpersonal relationships within the counseling settings. Thus, the aim of this research is to examine school counselors' ambivalent sexism in the context of interpersonal relationships and attributional complexity. For this purpose, the relationships between interpersonal relationship dimensions (empathy, approval dependence, trust others, and emotional awareness), ambivalent sexism, and attributional complexity were analyzed. Ambivalent Sexism Inventory, Attributional Complexity Scale, and Scale of Interpersonal Relationship Dimensions were used as instruments. With a sample of 340 school counselors from Istanbul, our findings indicate that ambivalent sexism, interpersonal relationship dimensions, and attributional complexity are correlated with each other on different levels. Furthermore, we found some unexpected results such as a high level of sexism and a low level of empathy accompanied by positive causal relationships between ambivalent sexism and empathy and emotional awareness. In the end, the findings of this study essentially aspire to raise awareness about the issue of sexism among prospective and working school counselors in addition to stressing the need for boosting empathetic attitudes.
\end{abstract}

Keywords: ambivalent sexism, attributional complexity, empathy, interpersonal relations, school counseling

Cite: Dinçer, F., Kenan, S., and Erden Çınar, S. (2021). Ambivalent sexism, interpersonal relationships and attributional complexity of school counselors in Istanbul. Anadolu Journal of Educational Sciences International 11(1), 323-339. DOI: 10.18039/ajesi.687143

\footnotetext{
${ }^{1}$ This research study was conducted based on the corresponding author's master thesis of MarmaraUniversity, Institute of Educational Sciences, dated 2016.

2 (Corresponding author) M.A., MarmaraUniversity, Faculty of Education, Department of Guidance and Psychological Counseling, Turkey, feyzadincer.marmara@gmail.com, https://orcid.org/0000-0002-6553-6928

3 Prof. Dr., Marmara University, Faculty of Education, Department of Educational Sciences, Turkey, seyfi.kenan@marmara.edu.tr, https://orcid.org/ 0000-0002-3773-7693

${ }^{4}$ Assoc.Prof., MarmaraUniversity, Faculty of Education, Department of Guidance and Psychological Counseling,

Turkey, seval.erden@marmara.edu.tr, https://orcid.org/ 0000-0002-4512-1274
} 


\section{Introduction}

School counselors have been affecting the education system as well as the school culture in many ways since they became a member of it. There are different suggestions about their roles in the school environment such as: being responsible for mental health, being an educator and also a guide. (Kuzgun, 2008).

According to the researchers (Korkut, 1997; Kuzgun, 2008; Yeşilyaprak, 2007), school counselors should follow some principles such as empathy which is to perceive, understand and accept other person's inner experiences in the concurrent moment (Bauman and Karel, 2013), awareness of individual differences, accepting that every human is valuable while respecting them, accepting that every human has the right to make their own decisions, not forcing people to change, respecting confidentiality, not revealing their clients'/ students' privacy, having democratic and egalitarian attitudes, putting client/ student at the center of their work. All these principles are the determinants of the quality of interpersonal relationships within the school climate. There is no doubt that school counselors need to internalize these principles to become effective and efficient.

School counselors work closely with students for promoting academic success and solving problems. This working environment puts interpersonal relationships in the center. While trying to build high quality interpersonal relationships with students, school counselors have to consider being sensitive to individual differences including race, ethnic group, gender, and socio-economic status (Miller, Taha and Jensen, 2013). This statement highlights a tie between interpersonal relationships, attributions and sexist attitudes from a cognitive perspective.

According to Heider's theory and Kelley's following attribution theory based on cognitive theories, humans seek understanding and controlling the world that they live in. Attribution theory suggests that people are rational; they make interpretations out of their experiences and act accordingly (Graham and Folkes, 1990). Attributions about gender roles have been studied in a research via virtual games. Participants played games against unknown gamers and they thought the gamer was a male when it was competitive and a female when it was collaborative. After the experiment, it has been noted that male gender has been attributed as "competitive" and female gender has been attributed as "helpful, collaborative" (King, Miles and Kniska, 1991).

Attitudes are positive or negative beliefs about a person, situation, object or an incident. Attitudes are cognitive concepts; they are pre-cognitions about things. According to the principles of counseling, school counselors should not have discriminative attitudes which in turn might affect interpersonal relationships negatively. Sexism, one of the dependents of this study, is the set of attitudes towards women which are beliefs about women's nature and their perceived values (Allyn and Treas, 2014).

Considering the principles that school counselors need to internalize, this study aims to investigate the relationships between ambivalent sexism, interpersonal relationship dimensions and attributional complexity. In this context, we would like to begin by clarifying the concepts of ambivalent sexism, interpersonal relationship dimensions and attributional complexity.

\section{Ambivalent Sexism}

Sex roles (or gender roles) are culturally shaped categories referring to rules of being male or female in a particular society. Sex roles are social concepts and they are generally stereotypes about how people act within their genders. Stereotypes are belief sets about a group which help people to understand the world, save energy by categorizing knowledge and help people to explain incidents or 
other people's behavior (McGarty, Yzerbyt and Spears, 2002; Stephan, 1989). Stereotypes about sex roles can also help people to understand their social reality and the world happening around them. But since they're generalized beliefs, they can also lead to discrimination. Sexism is discrimination based on people's genders and biases about their genders (Helgeson, 2009). Glicke and Fiske (1996) suggested a sexism concept that has two dimensions: Hostile Sexism and Benevolent Sexism. These two forms of sexism together created the concept of Ambivalent Sexism. Glick and Fiske (1997) used the "stick and carrot" analogy to explain the dual nature of ambivalent sexism. The "stick" refers to the hostile sexism which punishes women who rebel to traditional gender roles assigned to them at birth. Hostile sexism tries to justify men's dominance over women in a traceable way (e.g., men should hold the leading positions in physics because women are not good at it). On the other hand the "carrot" refers to something milder from the outside but harmful from nature; benevolent sexism. Benevolent sexism urges women to know their place by rewarding them (Chapleau, Oswald and Russell, 2007).

Hostile Sexism: Hostile sexism is identified with hostile attitudes towards women. It's generated from traditional sexism and it locates women in a lower social status than men. It's aggressive and it includes biases toward women (Fernandez, Castro and Lorenzo, 2002). Hostile sexism holds the beliefs such as "women are striving for gaining power over men" (Taşdemir and Sakall1-Uğurlu, 2010).

Benevolent Sexism: Benevolent sexism suggests that women are more social, adaptable, caring, naive, and fragile than men in a paternalistic concept. It affects women's social positions negatively because it states that women are weak and need men's protection (Ruth and Napier, 2014). Benevolent sexism hides its sexist beliefs under a "chivalry" cover. For example helping a woman carrying her purse, giving your seat to a woman in a bus, holding a woman's chair and many other behaviors socially accepted like those have cognitive roots about women's weaknesses. These beliefs are not supposed to be hostile or offensive; they generally seem naive and harmless, even moral (depending on the culture). But they're coming from the same sources which are creating hostile sexism. Source of benevolent sexism perceives women as sacred, romantic love object, love provider and child care (Glick and Fiske, 1996). Benevolent sexism might also offer the idea that women are morally superior to men arising from perceiving women as the innocent, furthermore, the vulnerable sex (Grubbs, Exline and Twenge, 2014). Ambivalent sexism stands in a place where people have both hostile and benevolent attitudes towards women at the same time; seeing them as manipulative females but also caregiver nurses.

\section{Attributional Complexity}

Humans are in need of explaining, understanding, predicting and controlling the world they live in. Having former ideas about social and natural phenomena helps people interpret them and predict what's in one step ahead. The term cognitive complexity has been used to refer to the cognitive processes people use to meet their mentioned needs to make sense of the world. Cognitive complexity expresses the process of using information (Esen Aygun, 2018). Cognitive complexity is generally presented in two categories: the complexity of differentiation and the complexity of integration. The complexity of differentiation refers to the number of factors and dimensions people use to understand or explain a phenomenon; the more dimensions are used the more the complexity is. The complexity of integration on the other hand is a much more dense type of complexity; it refers to the connections between the differentiated characteristics. Studies show that high level of complexity means people tend to have more than one option while making sense of phenomena; on the contrary having low levels of cognitive complexity refers to more rule-based, rigid ways of thinking (Fletcher and Reeder, 1986).

After considerable research and measurements are done about cognitive complexity, Fletcher and Reeder (1986) decided that there was a need for a different measurement than the former ones due 
to the lack of attributional schemata of cognitive complexity measurements. Driven from cognitive complexity, attributional complexity has seven domains which explain the term as a whole concept (Lakshman, 2013):

Level of interest for causal reasoning, preferring complex explanations over the simple explanations, metacognitions concerning explanations, being aware of external causes of behavior/ situation, a tendency to infer complex internal attributions (such as determining beliefs and attitudes), a tendency to infer complex external attributions (such as determining the proximal and distal environments), a tendency to infer external temporal causes.

Attribution theories emphasize individuals' explanations about incidents, behaviors, objects, people and so on. Attributional complexity refers to the complexity level of these explanations. There are individual differences in attribution processes; some people prefer more complex explanations, whereas some prefer simpler ones (Buluş, 2001).

People make attributions about other people around them every day. They try to understand them and act in a proper way. These attributions (including attributions about sex role stereotypes) help people have attitudes, opinions, and predictions when they interact with other people. This shows us how attributional complexity is a part of interpersonal relations (Baker, 1999; Heider, 1958). Since the high level of attributional complexity includes more factors to explain things, it is expected to be seen with success in interpersonal relations.

\section{Interpersonal Relationship Dimensions}

The science of psychology has been improving with different models of understanding human and animal behaviors. One of these models is the Interpersonal Model (Klerman, 1989). The interpersonal model aims to understand and predict human behaviors within their relations with other humans. Interpersonal relationship means an interaction between two or more people (Erden İmamoğlu, 2009). Interpersonal relationships have been investigated from different angles in the research area. In this research a cognitive approach (attribution theory) was used due to its eligibility to explain the concepts of sexism, attributional complexity, and interpersonal relations from the same perspective. Attribution theory is based on causative predictions as mentioned before; understanding or predicting human behavior is the way to understand human and act in a proper way, in other words, attributions are likely to interact with interpersonal relationships.

There have been two different explanations about the interpersonal relationships regarding sex; the first one claims the biological differences between men and women play a key role in this relationship while the second one focuses on gender roles and social learning. The latter view of Winstead and Derlega (1993) discusses feminine and masculine gender roles. Accordingly, feminine gender roles have enunciative orientation while the masculine gender roles have instrumental orientation. As a result, being empathetic in a relationship is expected from feminine gender roles whereas being autonomous is expected from masculine gender roles. A person can have feminine and/ or masculine gender roles regardless of their sex; having both feminine and masculine gender roles is called androgynous gender role. Furthermore being androgynous is found to be more successful in interpersonal relationships (İmamoğlu, 2008).

Interpersonal relationships are examined under four dimensions which are considered the factors determinate the quality of the relationships. These dimensions are approval dependence, empathy, trust others and emotional awareness. 
Approval dependence implies the ability to be autonomous, independent; making independent decisions, valuing themselves versus desiring approval from others, not being able to make independent decisions or being spontaneous in interpersonal relationships. Despite the negative sound of the name, approval dependence is considered a positive factor for interpersonal relationships regarding the Turkish culture. According to Kağıtçıbaşı (1990) dependency is a desired characteristic in Turkish culture due to the communal structure of the culture and the strong bonds within the families; therefore dependency does not function as a failure in interpersonal relationships. Although having a balance between individual and communal cultures is considered to be a better model with regards to relationships (Kağıtçıbaşı, 1990). Empathy is described by Rogers (1983) as being able to understand another person's feelings and thoughts accurately and reflect this understanding to the related person. Empathy, having both cognitive and affective components is the core of healthy interpersonal relationships. Trust others implies trusting other people within interpersonal relationships. The word "trust" has been explained in more than one ways in history of psychology; one view describes trust as a healthy personality trait (Erikson, 1982) whereas another one (Rotter, 1967) claims "trust" is generalization of expectations from a person or a group of people. Emotional awareness which is the last dimension of interpersonal relationships is consisted of controlling the feelings such as expressing one's own feelings and acting accordingly to the feelings (İmamoğlu, 2008).

Based on the literature it was aimed to see the relationships between ambivalent sexism, interpersonal relationship dimensions and attributional complexity. Our hypotheses are:

1. There are relationships between ambivalent sexism, attributional complexity and interpersonal relationship dimensions.

2. The quality of interpersonal relationships can be explained by attributional complexity.

3. Ambivalent sexism can be explained by attributional complexity through interpersonal relationship dimensions.

\section{Research Method}

\section{Method}

This study was conducted as a quantitative research. The existing state of the data and correlations between them were described by using relational screening model. Additionally path analysis was made using Mplus statistic program. Path analysis is a statistical method of structural equality model (SEM) and it aims to investigate the causal connections between variables.

\section{Study Group}

The population of the research was the school counselors working in Istanbul at the time. Convenience sampling was used, lead author of the research being a school counselor, used her connections to reach out other school counselors in İstanbul and collected data from the volunteers; as a result the sample was made of 340 school counselors; 242 women and 98 men. The description of the participants is presented in Table 1. 
Table 1. Demographic characteristics of participants

\begin{tabular}{|c|c|c|}
\hline Demographics & $f$ & $\%$ \\
\hline \multicolumn{3}{|l|}{ Gender } \\
\hline Women & 242 & 71,2 \\
\hline Men & 98 & 28,8 \\
\hline \multicolumn{3}{|l|}{$\begin{array}{l}\text { Years in } \\
\text { Profession }\end{array}$} \\
\hline $0-5$ & 264 & 77,6 \\
\hline 6- 10 & 56 & 16,5 \\
\hline $11+$ & 20 & 5,9 \\
\hline \multicolumn{3}{|l|}{ Age } \\
\hline 24- 34 & 322 & 94,7 \\
\hline $35-45$ & 16 & 4,7 \\
\hline $46+$ & 2 & 6 \\
\hline
\end{tabular}

\section{Instruments}

Ambivalent Sexism Inventory (Sakallı Uğurlu, 2002), Attributional Complexity Scale (Buluş, 2001), and Scale of Interpersonal Relationship Dimensions (İmamoğlu, 2008) were used as measurement. Moreover, personal information sheet including demographical variables was also used to gain demographical information.

\section{Ambivalent Sexism Inventory}

This scale was created in 1996 by Glick and Fiske (1996). The inventory was adapted into Turkish and validity and reliability tests of the translated version were conducted by Sakallı Ugurlu (2002). The Cronbach Alpha coefficient of the Turkish form has been found .85 and test- retest reliability coefficient has been found .87. The correlation between Ambivalent Sexism Inventory and sex role stereotyping of Burt has been found .60 .

Ambivalent Sexism Inventory is a 1 to 6 Likert scale. The scale has 22 items in total; 11 items measuring sub-scale of hostile sexism, and 11 items measuring sub-scale of benevolent sexism. Total score measures ambivalent sexism. Benevolent sexism also has three sub-scales which can be measured independently. These sub-scales are protective paternalism, complementary gender differentiation and heterosexual intimacy.

\section{Attributional Complexity Scale}

The scale is originally created by Fletcher and Reeder (1986). The Turkish version of the scale was adapted by Buluş (2001). The Turkish version's Cronbach Alpha internal consistency coefficient is .78. The correlation between The Attributional Complexity Scale and The Rational- Experiential Inventory of Epstein has been found .57 as a validity score. Marking items of the scale are varying from "I completely disagree" to "I completely agree". It's a seven point Likert scale. The scale has 28 items 
and seven factors making the main factor (attributional complexity) together. Higher scores show higher levels of attributional complexity.

\section{Scale of Interpersonal Relationship Dimensions}

This scale is developed by İmamoğlu (2008) aiming to predict interpersonal relationships and to determine interpersonal relationships dimensions within Turkish culture. It's a five point Likert scale. The scale has four factors: approval dependence, empathy, trust others, and emotional awareness. The factors explained $36 \%$ of the total variance together. High scores in every factor show higher levels on the relevant factor. The Cronbach Alpha coefficients of the sub- scales change between .78 and .85 and test- retest coefficients change between .62 and .96 .

\section{Limitations}

This study is limited in the sampling chosen from the school counselors who were working in İstanbul in 2016. The data collection of the study is limited in the demographic information sheet, Ambivalent Sexism Scale, Attributional Complexity Scale, and Scale of Interpersonal Relationship Dimensions.

\section{Ethical Issues}

The privacy and anonymity of the participants were prioritized. Identifying information such as name and surname were not collected during the study. The participants were subjected to no harm. Only the voluntary school counselors were included in the study and before starting they consented to join by checking a box stating the purpose of the study and explaining the data confidentiality. The data collected from them were not shared with third parties to provide confidentiality.

This study had no funding and there is no conflict of interests.

\section{Findings}

Before testing the model by using path analysis, correlations of the research variables was tested and the results are presented in Table 2 .

Table 2. Correlations between the sub-scales of Ambivalent Sexism Inventory and the sub-scales of Attributional Complexity Scale

\begin{tabular}{|c|c|c|c|c|c|c|c|c|}
\hline & $\begin{array}{l}\text { Motivation } \\
\text { Component }\end{array}$ & $\begin{array}{c}\text { Complex } \\
\text { vs. Simple }\end{array}$ & Metaco. & $\begin{array}{c}\text { Int. } \\
\text { With } \\
\text { Others }\end{array}$ & $\begin{array}{c}\text { Abstract } \\
\text { vs. } \\
\text { Casual }\end{array}$ & $\begin{array}{c}\text { External } \\
\text { Causes }\end{array}$ & $\begin{array}{c}\text { Past } \\
\text { Causes }\end{array}$ & $\begin{array}{c}\text { Attr. } \\
\text { Complx }\end{array}$ \\
\hline $\begin{array}{l}\text { Hostile } \\
\text { Sexism }\end{array}$ &,$- 17 * *$ &,$- 17 * *$ &,- 04 &, 02 &,- 07 &,- 08 &,- 02 &,$- 13 *$ \\
\hline $\begin{array}{l}\text { Benevolent } \\
\text { Sexism }\end{array}$ &, 04 &,$- 13^{*}$ & ,06 & ,11* &,$- 14 *$ & ,06 &, 03 &, 04 \\
\hline
\end{tabular}


Table 2. (continued)

\begin{tabular}{|c|c|c|c|c|c|c|c|c|}
\hline $\begin{array}{l}\text { Heterosexual } \\
\text { Intimacy }\end{array}$ &, $53 * * *$ &, $56 * * *$ &, $38 * * *$ &, $32 * * *$ &, $20 * * *$ &, $72 * * *$ & ,07 &, $67 * * *$ \\
\hline $\begin{array}{l}\text { Protective } \\
\text { Paternalism }\end{array}$ &, $41 * * *$ &, $51 * * *$ &, $72 * * *$ &, $36 * * *$ &, $22 * * *$ &, $56 * * *$ &, $11 *$ &, $71 * * *$ \\
\hline $\begin{array}{l}\text { Comp. } \\
\text { Gender D. }\end{array}$ &, $75 * * *$ &, $\mathbf{3 0} * * *$ &, $32 * * *$ &, $38 * * *$ &, $27 * * *$ &, $26 * * *$ &,$- 11 *$ &, $56 * * *$ \\
\hline $\begin{array}{l}\text { Ambivalent } \\
\text { Sexism }\end{array}$ &,- 08 &,$- 17 * *$ &,- 00 & ,09 &,$- 14 *$ &,- 02 &, 00 &,- 05 \\
\hline$p<.05$ & & & & & & & & \\
\hline $\begin{array}{l}* * p<.01 \\
* * * p<.001\end{array}$ & & & & & & & & \\
\hline
\end{tabular}

As can be seen from Table 2 many correlations were found between ambivalent sexism and attributional complexity. Hostile sexism was negatively correlated with attributional complexity on many sub-scale levels. Sub-scales of benevolent sexism were found positively correlated with attributional complexity.

Table 3. Correlations between the sub-scales of Ambivalent Sexism Inventory and the sub-scales of scale of interpersonal relationship dimensions

\begin{tabular}{|c|c|c|c|c|}
\hline & $\begin{array}{c}\text { Approval } \\
\text { Dependency }\end{array}$ & Empathy & $\begin{array}{l}\text { Emotional } \\
\text { Awareness }\end{array}$ & Trust others \\
\hline $\begin{array}{l}\text { Ambivalent } \\
\text { Sexism }\end{array}$ &, $21^{* *}$ & ,07 &,- 03 &,$- 14^{* *}$ \\
\hline $\begin{array}{l}\text { Complementary } \\
\text { Gender } \\
\text { Differentiation }\end{array}$ &,- 10 &, $38^{* *}$ &, $1^{*}$ &, $\mathbf{1 8}^{* *}$ \\
\hline $\begin{array}{l}\text { Protective } \\
\text { Paternalism }\end{array}$ &,- 03 &, $24^{* *}$ & ,09 &, $1^{*}$ \\
\hline $\begin{array}{l}\text { Heterosexual } \\
\text { Intimacy }\end{array}$ &,- 04 &, $27^{* *}$ &, $17^{* *}$ & ,09 \\
\hline Benevolent Sexism &, $18^{* *}$ &, $1^{* *}$ & ,03 &,- 07 \\
\hline Hostile Sexism &, $17^{* *}$ &,- 04 &,- 07 &,$- 17^{* *}$ \\
\hline
\end{tabular}


Several correlations have been found between ambivalent sexism sub-scales and interpersonal relationships dimensions. In Table 3 it can be seen that overall ambivalent sexism was found positively correlated with approval dependency $(\mathrm{p}<.01)$ and negatively correlated with trust others $(\mathrm{p}<.01)$. All the sub-scales of benevolent sexism and overall benevolent sexism was found correlated with the empathy factor of interpersonal relationship dimensions $(\mathrm{p}<.01)$. Emotional awareness was found positively correlated with two sub-scales (complementary gender differentiation and heterosexual intimacy) of benevolent sexism whereas trust others was found negatively correlated with hostile sexism $(\mathrm{p}<.01)$ and positively correlated with complementary gender differentiation $(\mathrm{p}<.01)$ and protective paternalism $(\mathrm{p}<.05)$.

Table 4. The correlations between overall Attributional Complexity score and interpersonal relationship dimensions

\begin{tabular}{lcccc}
\hline & $\begin{array}{c}\text { Approval } \\
\text { Dependency }\end{array}$ & Empathy & $\begin{array}{c}\text { Emotional } \\
\text { Awareness }\end{array}$ & Trust others \\
\hline $\begin{array}{c}\text { Attributional } \\
\text { Complexity }\end{array}$ &,- 02 & $\mathbf{, 3 5}^{* *}$ & $\mathbf{1 4}^{* *}$ & $\mathbf{1 2}^{*}$ \\
$* * p<.01$ & & & & \\
$* p<.05$ & & & &
\end{tabular}

As can be seen from Table 4, attributional complexity was found positively correlated with empathy, emotional awareness and trust others. It means a higher level of attributional complexity comes with a higher level of empathy, emotional awareness, and trust others.

The main aim of the study was to investigate the relationships between ambivalent sexism, attributional complexity and interpersonal relationship dimensions. The results indicated that they are related to each other, significantly. This is the assumption of the path analyses. Since this assumption was met path analysis of structural equation model (SEM) was used in order to further investigate these correlations and explain the relationships between them.

\section{Path Analysis}

The correlation analyses showed that there were significant relationships between our variables which led us draw a preliminary picture of the causal relationships between them. After putting several assumptions to test on Mplus in order to explain a set of causal relationship between our variables, we found the most significant causal explanation model (Table 5) (Figure 1).

Table 5. Path analysis for attributional complexity, ambivalent sexism and interpersonal relationship dimensions

\begin{tabular}{cccc}
\hline $\begin{array}{c}\text { Chi Square } \\
(\boldsymbol{p})\end{array}$ & RMSEA & CFI & SRMR \\
\hline 0,92 & 0,04 & 1 & 0,001 \\
\hline
\end{tabular}




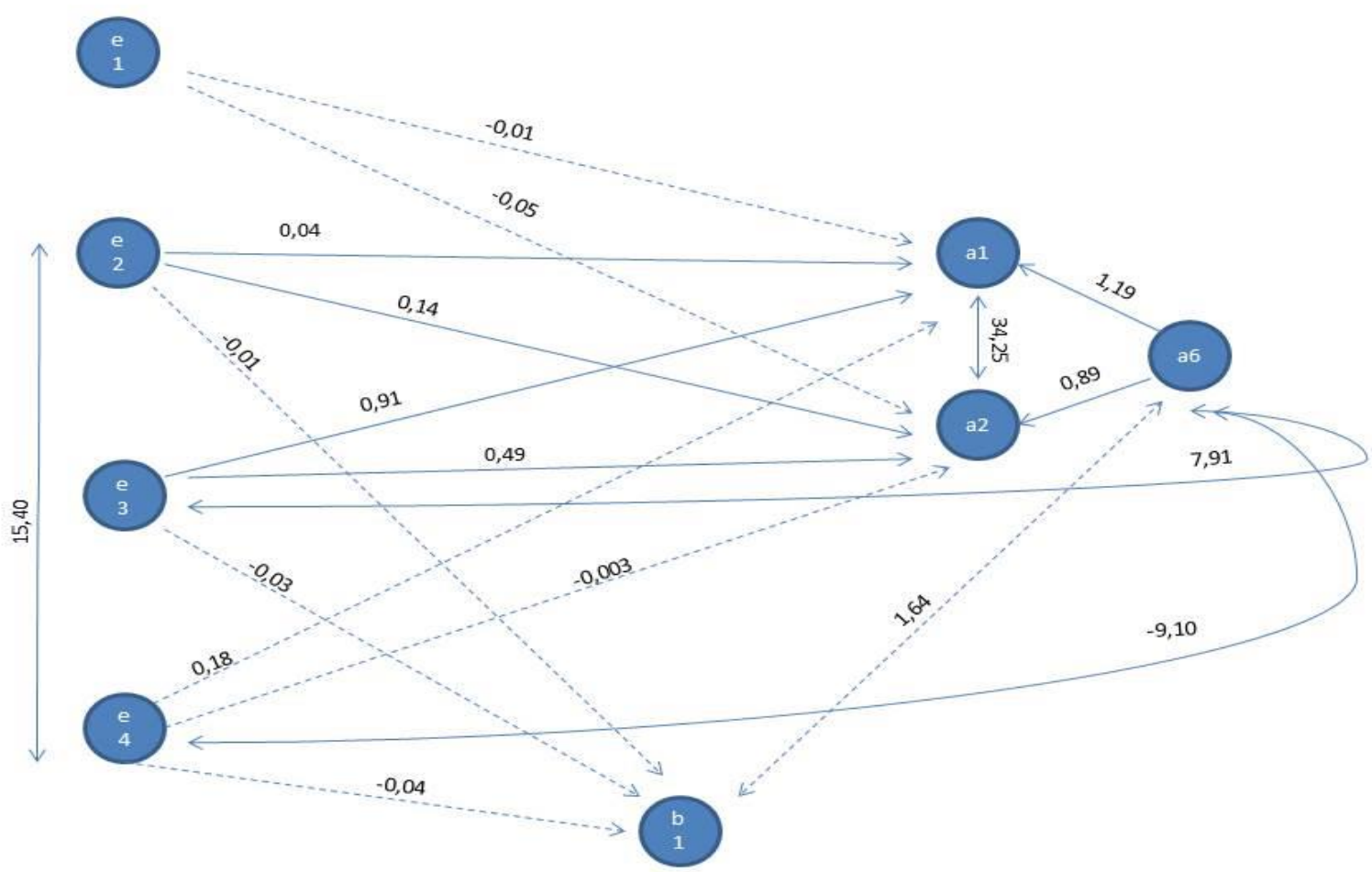

Figure 1. Path analysis made to understand causal relationships between attributional complexity, ambivalent sexism and interpersonal relationship dimensions

e1: Approval dependency $>$ one-way effect, significant relationship

e2: Empathy

e3: Emotional awareness

----------->one-way effect, insignificant relationship

e4: Trust others

b1: Attributional complexity

$\longleftrightarrow$ reciprocal effect, significant relationship

a1: Hostile sexism

a2: Benevolent sexism

$\longleftrightarrow-\cdots \rightarrow$ reciprocal effect, insignificant relationship

a6: Ambivalent sexism

Our expectation, which suggests that the quality of interpersonal relationships can be explained by attributional complexity, did not give us significant causal relationships between these variables. Nevertheless, significant causal relationships were found between empathy, emotional awareness and hostile and benevolent sexism. Additionally, emotional awareness and trust others were found reciprocally related to ambivalent sexism. In the end, our third hypothesis was not confirmed as well considering attributional complexity was not a cause for ambivalent sexism. Nevertheless, what we can interpret from Figure 1 are: 
-Empathy explains hostile and benevolent sexism,

-Emotional awareness explains hostile and benevolent sexism,

- Emotional awareness and ambivalent sexism explain each other,

- Trust others and ambivalent sexism explains each other negatively. Which means if trust on other people is low ambivalent sexism will be high,

-Empathy and trust others explain each other and empathy explains ambivalent sexism through trust others,

- Attributional complexity is not a significant factor explaining neither interpersonal relationships nor ambivalent sexism.

Besides defining the causal relationships, the effect of demographical variables on variables were also examined. Gender and years in the profession were taken into consideration. Due to the big differences between participant numbers within each group, a non- parametric test (Mann-Whitney U) was used for comparing means of collected data. The results are showed in Table 6.

Table 6. Mann-Whitney $U$ analyses to measure gender differences on sexism

\begin{tabular}{|c|c|c|c|c|c|c|c|}
\hline Scale & Group & $N$ & $\Sigma$ rank & Mean rank & $\mathbf{U}$ & $\mathbf{Z}$ & $\mathbf{p}$ \\
\hline \multirow{3}{*}{ Hostile Sexism } & Women & 242 & 35750 & 148,96 & & & \\
\hline & Men & 98 & 21541 & 219,81 & 6830 & $-6,05$ &, 000 \\
\hline & Total & 340 & & & & & \\
\hline \multirow{3}{*}{$\begin{array}{l}\text { Benevolent } \\
\text { Sexism }\end{array}$} & Women & 242 & 38629 & 159,62 & & & \\
\hline & Men & 98 & 19341 & 197,36 & 9226 & $-3,21$ &, 001 \\
\hline & Total & 340 & & & & & \\
\hline \multirow{3}{*}{$\begin{array}{l}\text { Heterosexual } \\
\text { Intimacy }\end{array}$} & Women & 242 & 42413 & 175,26 & & & \\
\hline & Men & 98 & 15557 & 158,74 & 10706 & $-1,41$ & , 157 \\
\hline & Total & 340 & & & & & \\
\hline \multirow{3}{*}{$\begin{array}{l}\text { Protective } \\
\text { Paternalism }\end{array}$} & Women & 242 & 43123 & 178,19 & & & \\
\hline & Men & 98 & 14847 & 151,50 & 9996 & $-2,28$ &, 022 \\
\hline & Total & 340 & & & & & \\
\hline \multirow{3}{*}{$\begin{array}{l}\text { Complementary } \\
\text { Gender D. }\end{array}$} & Women & 242 & 43171 & 178,39 & & & \\
\hline & Men & 98 & 14799 & 151,01 & 9948 & $-2,35$ & ,019 \\
\hline & Total & 340 & & & & & \\
\hline \multirow{3}{*}{$\begin{array}{l}\text { Ambivalent } \\
\text { Sexism } \\
\text { (Overall scores) }\end{array}$} & Women & 242 & 36058 & 150,24 & & & \\
\hline & Men & 98 & 21233 & 216,66 & 7138 & $-5,67$ &, 000 \\
\hline & Total & 340 & & & & & \\
\hline
\end{tabular}

In terms of gender, results showed that emotional awareness which is a sub-scale of Scale of Interpersonal Relationship Dimensions was higher among women participants $(\mathrm{p}<.01)$. Women also had higher scores than men on attributional complexity $(\mathrm{p}<.001)$. After analyses, men were found significantly more sexist than women $(\mathrm{z}=-5,67 ; \mathrm{p}<.001)$. Men scored higher than women in hostile 
sexism, benevolent sexism sub-scales, and overall ambivalent sexism scale. Additionally, women's protective paternalism and complementary gender differentiation levels found significantly higher than men $(\mathrm{p}<.05)$ (Table 6).

In order to analyze the effect of years in the profession, Kruskal Wallis test was used. The results indicated that no significant differences were found in interpersonal relations dimensions and attributional complexity. On the other hand, participants who had been working in the profession 6-10 years were found more protective paternalist than others, but significance was not very strong $(\mathrm{p}<.05)$. Most of the variables also did not differ among age groups. The only difference found between age groups was on empathy. 24-34 (the youngest group) had higher empathy level, but significance was not strong $(\mathrm{p}<.05)$.

\section{Conclusion, Discussion and Suggestions}

School counselors engage in communications with students, teachers, and parents in every work day. The school environment they work in is a small version of the society they live in. The essential tool school counselors use in that environment is communication. Hence communication is the key factor for building a democratic society, according to Dewey (1927), as it fosters community and communality. Empathy, emotional awareness, attitudes without biases, being able to think out of stereotypes is required characteristics for a healthy relationship. Thus, school counselors need to have such characteristics.

Our findings indicate that ambivalent sexism, interpersonal relationship dimensions and attributional complexity are correlated with each other on different levels. For example, we found that hostile sexism was negatively correlated with many sub- scales of attributional complexity (Table 2), overall ambivalent sexism was found positively correlated with approval dependency (Table 3) and attributional complexity was found positively correlated with empathy, emotional awareness and trust others (Table 4).

This study has revealed that levels of empathy and emotional awareness among school counselors in İstanbul are surprisingly lower than desired. This result is surely worrying, and one cannot help but to affirm if the degree programs of psychological counseling spend enough effort in promoting empathy skills for prospective school counselors. And even though they do, these results may still be seen; because these kinds of skills should be taught in early childhood. University level may be too late for teaching empathy skills and giving a notion of emotional awareness. School counselors who had not learned these skills at early ages might have had low empathy and emotional awareness.

Attributional complexity is the richness of attributions and reasoning when trying to give meaning to incidents, situations or people (Fletcher and Reeder, 1986). In other words people with high attributional complexity concern about many more factors when giving meanings to things while people with low attributional complexity might look at things simpler and miss some crucial details. Low attributional complexity may mislead people by underestimating important factors. The attributional complexity level of participants has been found slightly higher than average. However, it is not as high as expected. School counselors face with situations they need to help people to solve every day. Thus they are expected to have high attributional complexity. Attributional complexity has been found correlated with interpersonal relationship dimensions such as empathy, emotional awareness, and trust others. Promoting these dimensions might be helpful to improve attributional complexity. Ambivalent sexism scores were found high among the school counselors as an unfavorable result for the school counseling profession. Putting high sexism, low empathy, and average attributional complexity together; it was expected to unveil connections between them. 
When it comes to discussing the results of correlation and path analysis it gets more complicated. First, we need to understand what we see in these results which are shown in the findings section of this article. We found out attributional complexity was explaining ambivalent sexism and explained by interpersonal relationship dimensions but they were not significant explanations (Figure 1). We built several different cause and effect models for attributional complexity and ran analyses to discover if it causes or caused by any of our variables; as a result we ended up with insignificant causal relationships. On the contrary, correlation analyses showed attributional complexity was related to empathy, emotional awareness, trust others and ambivalent sexism. Failure to prove a cause effect relationship between them might be interpreted by existence of unknown variables; the variables that we didn't have in our study. Or it can simply be said that they are related, they change together but one does not cause the other.

The most significant outcomes we realized were that empathy and emotional awareness were explaining ambivalent sexism in a positive way. It means being empathetic or/ and having emotional awareness were the determinants of being ambivalent sexist. But it contradicts the existing literature (Sakalli-Uğurlu, Yalçın and Glick, 2007) and our predictions beforehand. So how can it be explained? How can it be discussed? In that point there come questions and predictions for future research. Maybe having hostile or benevolent attitudes is not relying on being empathetic or having emotional awareness. Maybe it rather requires awareness about sexism with all versions and gender related issues in the society. Gender awareness is to recognize gender inequality and acknowledge discrimination against women (Martinez, Paterna, Roux and Falomir, 2010). Martinez et al. (2010) states that gender awareness can be achieved through acquiring a feminist identity and adds that one way of acquiring a feminist identity is to have liberal attitudes about gender roles, recognition of discrimination against women and the existence of sexism. Our research found positive correlations between sub-scales of benevolent sexism and empathy; with regards to that result, can we say that our research group was not aware of the benevolent face of sexism? Can we say that we cannot trace benevolent sexism yet we perceive it as an empathetic action towards women who are supposedly fragile and morally superior to men? On the other hand, a study investigating the role of empathy on victim blaming in male-female sexual harassment, it was found that participants who shown more empathy for the perpetrator were to blame the victim more than the others (Bongiorno, Langbroek, Bain, Ting and Ryan, 2019). This result implies that being empathetic does not necessarily mean being sensitive and aware about discrimination against women.

On the other hand, differentiation analyses indicated that women have had higher skills of interpersonal relationships. This can be explained by the way families and society raise female children. Gender roles and stereotypes might be effective in this result. Women are supposedly easy going due to gender roles. Women also have had scored higher than men on the attributional complexity scale supporting previous research (Foels and Reid, 2010; Tam, Au and Leung, 2008). Women prefer complex explanations to the incidents happening around them. They tend to use more factors while trying to understand the conditions beyond what is seen. Women take account of interactions with other people when they attribute. This finding also can be explained by traditional gender roles that women were born in. Roles that have been given to women are the healer, feeder, caregiver, listener etc. since the very early ages. Internalization of these roles might be an explanation for the high attributional complexity of women.

Men have been found more sexist than women. Former studies have verified this result (Işık, 2008). Unexpectedly women's protective paternalism and complementary gender differentiation have been found higher than men. Protective paternalism and complementary gender differentiation may be a representation of the acceptance of biological differences between women and men. If so, it can be said that women perceive themselves biologically different than men, and it seems that women are 
pleased with masculine protection and benevolence. Results also showed that more experienced school counselors (6-10 years) had higher protective paternalism than less experienced school counselors (0-5 years). Another finding is that younger participants (ages of 24-34) had higher empathy than older participants (age of 35+). These two findings might be explained by changing culture of Turkish society and generation gap.

To sum up, it is clear that the population of this sampling group need to be investigated further in the context of ambivalent sexism and interpersonal relationship dimensions in order to have a deeper understanding of the situation of being ambivalent sexist and low on empathy. Only after that we can know how to approach and manage the problem in an appropriate way. For future researches it is important to study the socio- cognitive elements of discriminative behavior such as sexism, and examine the ways to channel interpersonal relationship qualities such as empathy and emotional awareness unto having egalitarian attitudes towards women. 


\section{References}

Allyn, R. and Treas, J. (2014). Attitudes toward women. In A.C. Michalos (Ed.), Encyclopedia of quality of life and well- being research (pp.289- 291). Dordrecht: Springer Science \& Business. Retrieved January 1, 2016, from https://www.springer.com/gp/book/9789400707528

Baker, L.R. (1999). What is this thing called "Commonsense psychology"? Philosophical Explorations, 1, 3 - 19. Retrieved January 1, 2016, from https://doi.org/10.1080/13869799908520962

Baumann L.C., Karel A. (2013) Empathy. In Gellman M.D., Turner J.R. (Eds.), Encyclopedia of Behavioral Medicine (pp.678). Springer, New York, NY. Retrieved January 1, 2016, from https://doi.org/10.1007/978-1-4419-1005-9_144

Bongiorno, R., Langbroek, C., Bain, P.G., Ting, M. and Ryan, M.K. (2019). Why women are blamed for being sexually harassed: The effects of empathy for female victims and male perpetrators. Psychology of Women Quarterly, 20(10), 1-17. Retrieved January 1, 2020, from https://journals.sagepub.com/doi/full/10.1177/0361684319868730

Buluş, M. (2001). Kişi algı ölçeğinin öğretmen adayları için güvenirlik ve geçerlik çalışması. Eurasian Journal of Educational Research, 5.

Chapleau, K.M., Oswald, D.L. and Russell, B.L. (2007). How ambivalent sexism toward women and men support rape myth acceptance. Sex Roles, 57, 131-136. Retrieved January 1, 2016, from https://doi.org/10.1007/s11199-007-9196-2

Dewey, J. (1927). The public and its problems. New York: Holt.

Erden İmamoğlu, S. (2009). Kişilerarası İlişkiler. İstanbul: Yeni İnsan Yayınevi.

Erikson, E. (1982). The life cycle completed. New York: Norton.

Esen Aygun, H. (2018). The relationship between pre-service teachers' cognitive flexibility and interpersonal problem solving skills. Eurasian Journal of Educational Research, 77, 105-128. Retrieved March 3, 2019, from https://ejer.com.tr/en/archives/2018-issue-77-476/the-relationship-between-pre-serviceteachers-cognitive-flexibility-and-interpersonal-problem-solvi

Fletcher, G.J.O. and Reeder, G. (1986). Attributional complexity: An individual differences measure. Journal of Personality and Social Psychology. Retrieved January 1, 2016, from https://doi.org/10.1037/0022$\underline{3514.51 .4 .875}$

Foels, R. and Reid, L.D. (2010). Gender differences in social dominance orientation: The role of cognitive complexity. Sex Roles, 62(9-10), 684-692. Retrieved January 1, 2016, from https://doi.org/10.1007/s11199-010-9775-5

Graham, S. and Folkes, V.S. (1990). Attribution theory: Applications to achievement, mental health, and interpersonal conflict. New York: Taylor and Francis Group Psychology Press. Retrieved January 1, 2016, from https://doi.org/10.4324/9781315807669

Glick, P. and Fiske, S.T. (1996). The Ambivalent Sexism Inventory: Differentiating hostile and benevolent sexism. Journal of Personality and Social Psychology, 70(3), 491-512.

Glick, P. and Fiske, S.T. (1997). Hostile and benevolent sexism: Measuring ambivalent sexist attitudes toward women. Psychology of Women Quarterly, 21(1), 119-135. Retrieved January 1, 2016, from https://doi.org/10.1111/j.1471-6402.1997.tb00104.X

Grubbs, J.B., Exline, J.J. and Twenge, J.M. (2014). Psychological entitlement and ambivalent sexism: Understanding the role of entitlement in predicting two forms of sexism. Sex Roles, 70, 209-220. Retrieved January 1, 2016, from https://doi.org/10.1007/s11199-014-0360-1

Heider, F. (1958). The psychology of interpersonal relations. New York: John Wiley\& Sons.

Helgeson, V. S. (2009). Psychology of gender ( $3^{\text {rd }}$ Ed.). Upper Saddle River: Pearson Education, Inc.

İmamoğlu, S. (2008). Genç yetişkinlikte kişilerarasi ilişkilerin cinsiyet, cinsiyet rolleri ve yalnızlık algısı açısından incelenmesi. (Yayımlanmamış Doktora Tezi). Retrieved from January 1, 2016, http://dspace.marmara.edu.tr/handle/11424/19530. 
Iş1k, R. (2008). The pedictors of understanding honor and attitudes toward honor related violance: Ambivalent sexism and system justification. (Unpublished Master Thesis). Retrieved from http://etd.lib.metu.edu.tr/upload/12609717/index.pdf.

Kâgitçibaşi, Ç. (1990). Family and socialization in cross-cultural perspective: A model of change. In J. J. Berman (Ed.), Current theory and research in motivation, Vol. 37. Nebraska Symposium on Motivation, 1989: Cross-cultural perspectives (pp. 135-200). Lincoln, NE, US: University of Nebraska Press. Retrieved January 1, 2018, from https://psycnet.apa.org/record/1990-98659-003

King, W.C., Miles, E.W. and Kniska, J. (1991). Boys will be boys (and girls will be girls): The attribution of gender role stereotypes in a gaming situation. Sex Roles, 25, 607-623. Retrieved January 1, 2016, from https://doi.org/10.1007/BF00289567

Klerman, G.L. (1989). The interpersonal model. In. J.J. Mann (Ed.), Models of depressive disorders (p. 45- 77). New York, NY: Plenum Press. Retrieved January 1, 2016, from https://doi.org/10.1007/978-1-4613$\underline{0831-7 \quad 3}$

Korkut, F. (1997). Rehberliğin ilkeleri ve demokrasi anlayışı. Ekonomik Yaklaşım, 8(27), 251- 258. Retrieved January 1, 2016, from http://www.ekonomikyaklasim.org/fulltext/94-1395517270.pdf?1608103200

Kuzgun, Y. (2008). Rehberlik ve psikolojik danışma. Ankara: Nobel.

Lakshman, C. (2013). Biculturalism and attributional complexity: Cross-cultural leadership effectiveness. Journal of International Business Studies, 44, 922-940. Retrieved January 1, 2016, from https://doi.org/10.1057/jibs.2013.36

Martinez, C., Paterna, C., Roux, P. and Falomir, J.R. (2010). Predicting gender awareness: The relevance of neosexism. Journal of Gender Studies, 19(1), 1-12. Retrieved January 1, 2018, from https://doi.org/10.1080/09589230903057142

McGarty, C., Yzerbyt, V.Y. and Spears, R. (2002). Stereotypes as explanations: The formation of meaningful beliefs about social groups. Cambridge University Press; Cambridge. Retrieved January 1, 2016, from https://doi.org/10.1017/CBO9780511489877

Miller L., Taha L. and Jensen E. (2013). From guidance to school counseling: New models in school mental health. In: Clauss-Ehlers C., Serpell Z., Weist M. (eds), Handbook of Culturally Responsive School Mental Health (pp. 43- 56). New York, NY: Springer. Retrieved January 1, 2016, from https://www.springer.com/gp/book/9781461449478

Rogers, C. R. (1983). Empatik olmak değeri anlaşılmamış bir varoluş şeklidir. (F. Akkoyun, Çev.). Ankara Üniversitesi, Eğitim Bilimleri Fakültesi Dergisi, 16(1), 103-123. Retrieved January 1, 2016, from https://doi.org/10.1501/Egifak_0000000929

Rotter, J.B. (1967). A new scale for the measurement of interpersonal trust. Journal of Personality, 35, 651-665. Retrieved January 1, 2016, from https://doi.org/10.1111/j.1467-6494.1967.tb01454.X

Ruth, L. and Nepier, J. (2014). Benevolent sexism. In A.C. Michalos (Ed.), Encyclopedia of quality of life and well- being research (pp.289- 291). Dordrecht: Springer Science+Business. Retrieved January 1, 2016, from https://www.springer.com/gp/book/9789400707528

Sakallı-Uğurlu, N. (2002). Çelişkili duygulu cinsiyetçilik ölçeği: Geçerlik ve güvenirlik çalışması. Türk Psikoloji Dergisi, 17(49), 47- 58. Retrieved January 1, 2016, from https://dergipark.org.tr/en/download/articlefile/48071

Sakallı-Uğurlu, N., Yalçın, Z.S. and Glick, P. (2007). Ambivalent sexism, belief in a just world, and empathy as predictors of Turkish students' attitudes toward rape victims. Sex Roles, 57(11-12), 889-895. Retrieved January 1, 2016, from https://doi.org/10.1007/s11199-007-9313-2

Stephan, W.G. (1989). Cognitive approach to stereotyping. In Bar- Tal et.al. (Ed.), Stereotyping and prejudice (pp.37- 57). New York: Springer Science \& Media. Retrieved January 1, 2016, from https://www.springer.com/gp/book/9781461281658

Tam, K.P., Au, A. and Leung, A.K.Y. (2008). Attributionally more complex people show less punitiveness and racism. Journal of Research in Personality 42 (4), 1074-1081. Retrieved January 1, 2016, from https://doi.org/10.1016/j.jrp.2007.11.002 
Taşdemir, N. and Sakall-Uğurlu, N. (2010). The relationships between ambivalent sexism and religiosity among Turkish university students. Sex Roles, 62(7-8), 420-426. Retrieved January 1, 2016, from https://doi.org/10.1007/s11199-009-9693-6

Yeşilyaprak, B. (2007). Eğitimde rehberlik hizmetleri. Ankara : Nobel. 